\title{
Towards a set of guidelines for the development of robust water-sharing systems
}

Michael D. Young, The University of Adelaide and Global Water Partnership, Stockholm

\section{Abstract}

A framework for the review of existing water management systems and their transformation into robust water sharing systems is offered. The framework focuses on the need to develop efficient and equitable ways to manage water scarcity and plan to deal with the tensions scarcity imposes on any community.

The framework identifies a way to bring together traditional community-managed systems with those typically used to allocate water to large water users and more commonly found in developed countries. So that use can be kept within sustainable limits while optimizing use, the framework includes mechanisms that enable the reallocation of water as demand and supply conditions change. Nonconsumptive uses are recognized and environmental objectives can be delivered efficiently.

Compliance with well-established accounting and hydrological concepts. Ways to increase the value of existing entitlements, encourage innovation and protect investments are included as options. It is recognized that the governance and legal arrangements necessary to underpin successful implantation are context specific.

\section{Introduction}

The United Nations (UN) Sustainable Development Goal 6 Synthesis Report on Water and Sanitation (UN, 2018) states that if pressures on water resources continue, by 2050 over half the world's population will be reliant on supplies that cannot be guaranteed. Aggravated by rising demands, adverse climate change and shifting populations, for many people water is no longer an abundant resources.

Defined variously as a lack of water security, water stress, water scarcity, a water shortage, and/or a drought - in all such cases the search for a solution must include the development of robust ways to manage access to and the use of water.

The Global Water Partnership hosts one of the world's richest databases of case studies and other information about integrated water resources management (IWRM) practices - the IWRM Toolbox. A quick search of this Toolbox, however, reveals few if any insights that can be used to assist water resource managers to design and improve their water-sharing arrangements. This is despite it being well known that weak water-sharing systems regularly result in over-use and, typically, are associated with social, economic, and environmental harm. A set of guidelines for the development of water sharing systems and the processes to be followed in transitioning from current to robust systems could do much to help water managers develop the case for such a transition, develop the necessary detail, secure the necessary political and administrative support and, having completed these steps, begin implementation.

\section{What is a robust water-sharing system?}

The development of robust water-sharing agreements is a necessary, but not sufficient, condition to avoid water security problems. In fact, the UN's 2018 Synthesis Report on progress towards Sustainable Development Goal 6 ("Ensure availability and sustainable management of water and sanitation for all") reminds readers that "the 2030 Agenda fully commits Member States to integrated water resources management and transboundary cooperation over shared water resources". And it points out that "putting IWRM into practice will be the most comprehensive step that countries make towards achieving SDG6". Robust water-sharing arrangements are a critical aspect of this work, and leaders at all levels of water governance - be this local, regional, provincial, and/or national - are well advised to integrate these arrangements within their water management systems.

So what is a 'robust' water-sharing system? The perspectives presented in this paper build on work by the OECD (2015b), Ostrom (2010), the Food and Agriculture Organization, the United Nations, Valuation Principles developed by the High-Level Panel on Water (2018) and many others interested 
in improving the way water resources are managed (See, for example, Wheeler et al. 2017; Young and McColl, 2005; Tang, 1992 and Bruns et al. 2005).

As Ostrom has reasoned, no-one should expect to discover a 'one size fits all' water-sharing system (Ostrom, 2010). Ostrom's many case studies, however, suggest that there are a number of common features (tests) that can be used to assess the robustness of existing arrangements and to assist readers to determine whether there might be merit in seeking an opportunity to improve them.

When water becomes scarce, water supply has to be managed; governments and communities are incentivised to begin searching for ways to make better use of the available resource and, where possible, increase the quantity of water that can be accessed (Turton, 1999).

\section{Step one: secure water supply}

When water is scarce, typically the first response to is to begin searching for more water by, for example, building a new dam and/or transferring water from one location to another. Sometimes, 'the evil day that the rubber hits the road' can be put off by accessing an under-utilised groundwater resource. These first steps buy time but, eventually, it becomes necessary to strengthen administrative arrangements, set system-wide limits, and agree on sharing rules.

China's decision to build the Three Gorges Dam and establish its South-North project is an example of this first step. Note also that these first steps have brought significant flood risk reduction and other benefits to many communities. China's testing of alternative water-sharing arrangements, including the development of water entitlement registers, provides an excellent example of this paper's prime recommendation that, in parallel with infrastructure and supply enhancing initiatives, there is a strong case for considering the benefits of improving or even totally re-designing underlying allocation, governance, and management arrangements. California's 2014 decision to make local agencies responsible for the management of its 127 most stressed groundwater basins is an example of this latter approach (Young and McAteer, 2017).

Usefully, the International Water Management Institute (Molden, 2007) has built a database that identifies those parts of the world where water scarcity is 'economic' rather than 'absolute' in the sense that the onset of absolute water scarcity can be delayed by increasing investment in dams and improving distribution arrangements. The World Resources Institute's Aqueduct Water Risk Atlas provides a useful tool that enables the interactive examination of the importance of developing robust water-sharing arrangements. ${ }^{1}$

\section{Step two: investing in demand and supply management measures}

As water scarcity increases and becomes more common and opportunities to increase storage and transfer water from one location to another are being exhausted or decrease, the second step (option) is to invest in measures that seek to reduce demand and increase the efficiency of supply. Typical mechanisms include:

- Awareness raising: use of persuasive and educational programmes that seek to change attitudes towards water use

- Regulations: introduction of regulations that restrict what are regarded as nonessential or wasteful uses of water

- 'Soft' incentives: institutional arrangements that encourage the more efficient use of water

Pricing: raising of supply charges and fees so that water users have an economic incentive to 'save' water

- Subsidies: use of transitional subsidies that encourage investment in more waterefficient technologies and equipment.

\footnotetext{
${ }_{1}^{1}$ See https://www.wri.org/resources/maps/aqueduct-water-risk-atlas
} 
Ultimately, and as demands grow, supplies decrease and/or droughts appear to become more common, water managers begin to search for ways to limit access and to share access. When the limiting and sharing arrangement is robust in the sense that it works well under pressure and also is seen to be fair, equitable, efficient, and sustainable, the case for change is minimal. When, however, the arrangements used to restrict access include temporary watering restrictions, hose-pipe bans, or moratoriums on well deepening and drilling, the case for change may be considerable.

The first insight offered in this paper is that whenever users sense that access to a water resource is about to be limited, amending an existing or putting in place a new system tends to become politically difficult (and expensive). Arguably, all parties will be better off if an agreement can be reached on the administrative changes that need to be made before absolute water scarcity and/or degradation become the norm. Judges at the 2018 World Water Forum confirmed this principle again: Prevention of harm is better (cheaper) than rehabilitation (Anonymous, 2018).

History has not served water managers well. Most water management systems and water right systems were developed when water was abundant. Existing systems have, hence, tended to evolve in a manner that did not plan for the emergence of scarcity or for emerging extremes as a result of changing hydroclimatic systems. As a result, many of the world's water management systems are poorly suited to the demands and changes that can now be predicted to occur in the coming years.

The global experience in the design of robust water-sharing systems is instructive (see, for example, Bruns et al., 2005; Tang, 1992; Young, 2010). A considerable amount can also be learned from mistakes made in, for example, the management of the rivers that flowed into the Aral Sea (Barghouti, 2006). This same literature is rich in advice about ways to consult with and include all parties in the search for a more robust set of water-sharing arrangements (Moore, 2018).

\section{Robustness}

Robust systems are designed to work in all circumstances including extreme circumstances. They are expected to withstand the test of time (Box 2). A robustly constructed dam will survive an earthquake. A robustly designed water-sharing system should enable water users to cope with the worst of droughts and include arrangements to enable the emergence of an adverse climate shift (Young and McColl, 2005).

There are many tests for the robustness of a water allocation system. At the most basic level, we would expect that during times of extreme stress, however defined, the system would allow rapid adjustment and encourage wise use. ${ }^{2}$ Typically, robust water-sharing systems also include mechanisms that allow the re-allocation of water from one sector to another and, also, one user to another.

\section{The development of robust water-sharing systems}

Although many water allocation systems seem to be failing, a number of historical examples of robust water-sharing systems have withstood the test of time. Usually, the core principles of these systems are easy to explain. As a general rule, they begin by making it clear that whenever supplies are limited:

- $\quad$ someone is authorised and allowed to take more water

- $\quad$ only when someone else agrees to and actually does take less water

Trusted governance systems are used to ensure that all users comply with this rule. It is interesting to note that these systems tend to have a high degree of practicality. Exceptions can be made and can be managed. Passing travellers, for example, can be allowed to take a drink without asking for permission to do so - provided that the amount they take and the total amount taken by all travellers is insignificant. Similarly, it is common for local people to be allowed to collect water and carry it back to their house for domestic purposes.

\footnotetext{
${ }^{2}$ 'Wise use' is a catch-all phrase for an outcome that optimises trade-offs between competing social, economic, and environmental objectives under conditions of uncertainty and in recognition that future as well as current consequences need to be considered.
} 
One of the oldest examples of relatively robust water-sharing arrangements can be found in the qanat systems that are known also as aflaj, foggara, fulaj, kareez, kanjering, and khettara systems. Initially developed in Persia and now found throughout the Middle East, Asia, and as far east as China, these systems bring scarce mountain water resources to lowland farms via a tunnel. In nearly all these systems, access rights are defined as an entitlement to a time-limited share of a varying flow on a rotational basis (Box 1). Appreciating the need for change and adaptation through time, shareholders are able to transfer some or all of the shares they hold and/or sell the flow allocated to these shares on a weekly or fortnightly basis. In all such sharing systems, it is clearly understood that once they have been created no more shares can be issued. ${ }^{3}$

In quite a few of these systems, the village also holds a share, so that maintenance can be funded using revenues received from the weekly or fortnightly sale of the water associated with the village's share. Institutional rules that stand out in these systems include arrangements that:

ensure that - if any user wants secure access to a larger share - they need to find someone who is prepared to accept a lesser share

- recognise that the volume of available water will change and that no country, district, town, or person can be given an absolute right to a guaranteed volume of water - flows must be expected to decline and, when this happens, the total volume taken must be reduced

- $\quad$ raise sufficient money to ensure that the system can be maintained locally without appeal to national or international sources of money.

\footnotetext{
${ }^{3}$ With the exception that, if a new water source is added permanently to the supply system, those that acted to create this new source can be issued shares in proportion to the size of the increase in the value to other shareholders of the contribution they make.
} 


\section{Box 1 Qanat irrigation systems}

The first qanat irrigation systems are thought to have been built around 2000-3000 years ago in Persia. Each of these systems uses a tunnel to transfer water from an aquifer in a mountain to a farming area and associated village.

Rights to access the flow, which varies continuously, is on a time-limited basis. In essence, each irrigator holds an entitlement to a share of the flow in any, say, 14-day period. Share ownership is defined by reference to a village book. Typically, the permanent transfer of part or all of a share is possible only by amending this book.

In large systems, a water master is used to manage the passage of flows from one field to another. As needs for water typically vary from week to week, the water master is responsible for facilitating the transfer of a flow from one user to another.

In quite a few systems, the village as a whole holds a share, so that it can use the money from the regular sale of the village share to fund maintenance and, of course, pay the water master.

Once proven as an effective way to share access to a scarce water resource, this technology soon moved throughout the civilised world to China, North Africa, South Europe, and, possibly, to the Americas. $^{5}$

\section{Probable diffusion of qanat technology}

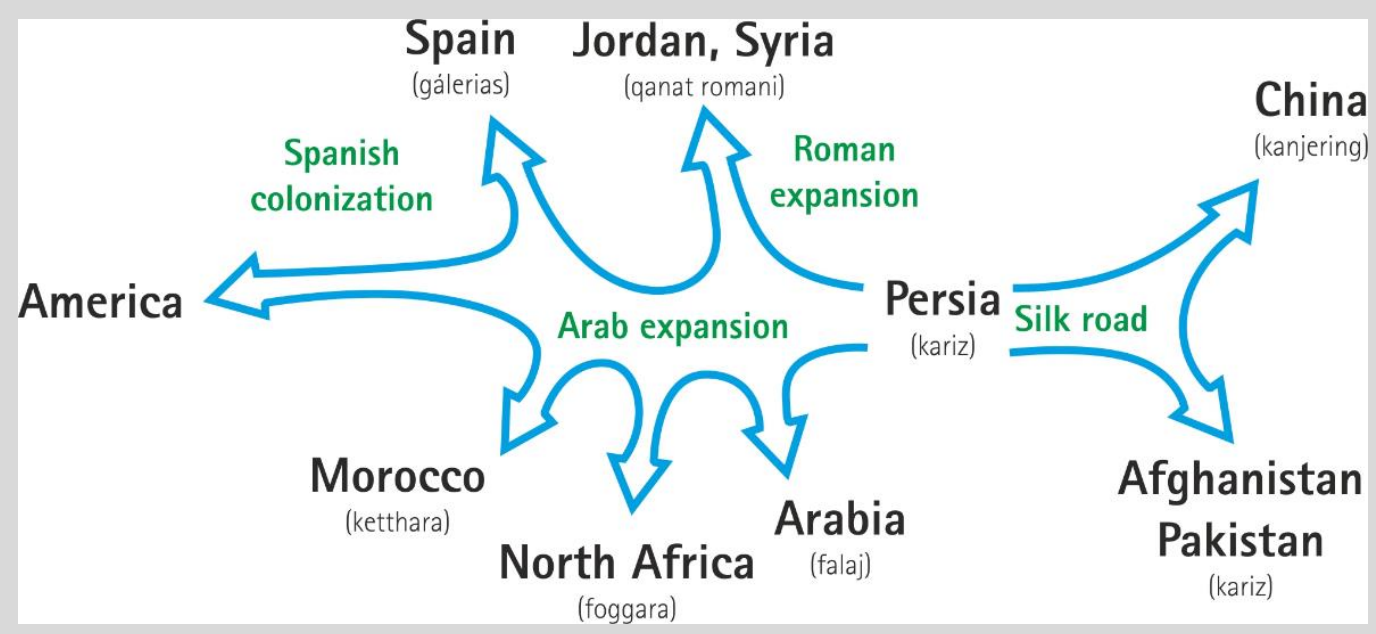

Adapted from Perry and Steduto (2017), Ward (1968), and Salaban personal communication (2018).

Centuries-old examples of robust water-sharing systems are also found in the tropics. In the Indonesian province of Bali, for example, Subak water-sharing arrangements were designed to ensure that each rice field receives its appropriate water allocation in a timely manner. Sharing and a strong sense of collective responsibility for maintenance are central to the success of the Subak system (Roth, 2011). Although no system we are aware of is perfect, more recent versions of attempts to put robust watersharing systems in place can be found in Australia's Murray-Darling Basin ${ }^{4}$ and in a few groundwaterdependent districts in the western USA. It is possible, also, to learn from other sectors. Many fisheries,

${ }^{4}$ In 2018, a television documentary revealed the extent of water stealing in one part of the basin and a group of respected scientists issued a declaration which, in essence, revealed the failure of environmental water recovery processes to account for return flows. In response, four states and the Federal Government and the Murray-Darling Basin Authority have commissioned more than 12 reviews in an effort to fix these deficiencies in the current regime. 
for example, are managed by issuing shares that entitle each shareholder to their pro-rata share of an annual catch entitlement. ${ }^{5}$ Similarly, in the corporate world and especially when there is considerable investment risk, dividends usually are distributed in proportion to the number of shares held (Young and McColl, 2005).

When water is abundant, discussions about the need for the development of robust water-sharing arrangements can be deferred. When water is scarce, however, limits on use have to be set and opportunities to access the limited water resource allocated and specified to ensure that future changes in demand and supply can be managed.

In practice, the most appropriate way to define shares and limit use requires careful consideration of cultural, legal, and social expectations and administrative norms. If crises are to be avoided, sharing arrangements have to be agreed among all relevant stakeholders - and respected. When these rules are disputed or, worse still, have not been worked out, then in times of scarcity disputes emerge - if left unresolved they tend to result in resource depletion, land subsidence, and environmental damage.

In large systems, local, regional, and system-wide limits may need to be set and sharing mechanisms designed to allow the amount of water that may be taken by each region and each local user to be varied as quickly as supplies change. That is, the sharing system has to have a hierarchical sense of administrative coherence, transparency, and impartiality.

Procrastination has high costs. In the United Kingdom, rather than waiting until over-allocation becomes a problem, it has been proposed that access to any water resource should be closed when permissions to access the resource reach around $70 \%$ of the estimated maximum average amount that can be allocated to users. At that time, the remaining $30 \%$ of entitlements should be placed in a reserve for subsequent allocation in a fair and equitable manner (Young, 2012).

\section{Water sharing and hydrology}

Before searching for practical guidelines for the development of robust water-sharing arrangements, some important, but often poorly understood, hydrological concepts need to be described.

\section{Climatic shifts occur and variability can increase}

The first seemingly obvious point is that sudden system-wide supply changes can and do occur. In many if not most regions, access to a nominated volume of water cannot be guaranteed.

One of the most recent examples of a sudden supply shock affected the city of Cape Town which in 20186, as Brisbane did in 2007 and Barcelona in 2008, was forced to face the fact that the urban water supply system, which they had come to trust, could run out of water.

In all three of these cases, the cause was described loosely as a ' 1 in a 1000-year drought' and a range of initiatives emerged. Each of these initiatives was designed to buy time and avoid a 'zero' day when water supplies would run out.

Arguably, one of the most informative of these experiences can be found in the Australian city of Perth where, in 1974, a sudden climatic shift occurred. At the time, the city's climate appears to have become permanently drier (see Figure 1). In fact, since 1974, inflows into Perth's main dam have never reached what, on the basis of the previous 70 years, was thought to be the average inflow. Two lessons emerge from this experience. First, adverse climate shifts can be sudden and may be permanent. Second, at least in dry Mediterranean climates like Perth's, the impact of reduced rainfall on run-off is very severe. The reason for this is that run-off only occurs after the land surface is wet. In Perth's case, a $21 \%$

\footnotetext{
${ }^{5}$ For a useful overview of the issues involved in the development of fish-sharing systems see the Environmental Defence Fund Tool kit available at http://fisherysolutionscenter.edf.org/resources/manuals-and-guides

${ }^{6}$ For a detailed description of all the strategies used to manage Cape Town's most recent 'crisis', see the City of Cape Town's Water $\quad$ Outlook $\quad$ Report $\quad 2018$ at http://resource.capetown.gov.za/documentcentre/Documents/City\%20research\%20reports\%20and\%20review/Water\%20Outloo k\%202018\%20-\%20Summary.pdf
} 
reduction in mean rainfall resulted in a three-fold reduction in run-off and, hence, a three-fold reduction in the quantity of water that flowed into its storage.

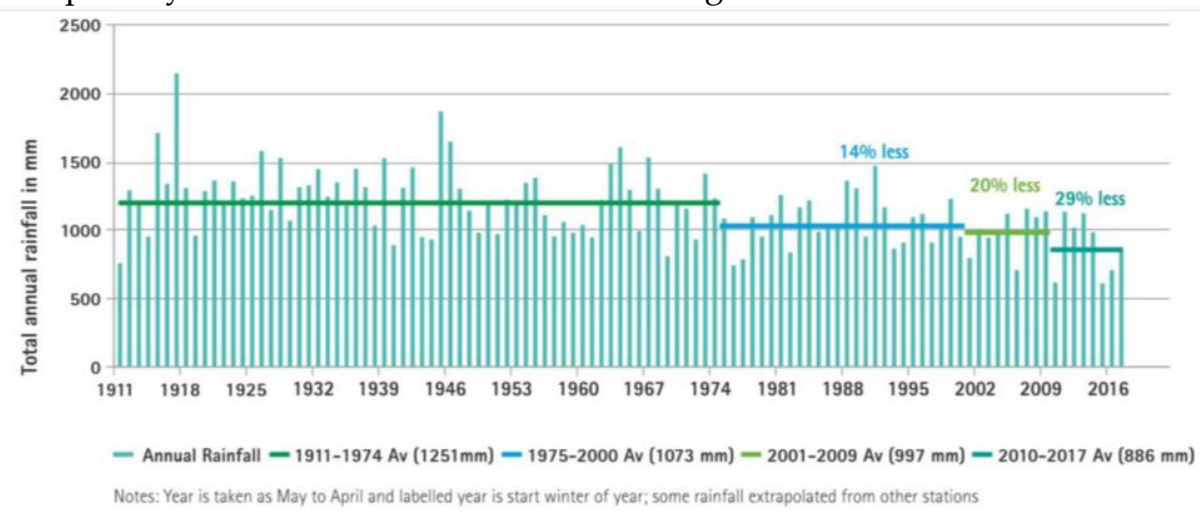

Stream inflows to dams - Percentage change relative to 1911-1974 average

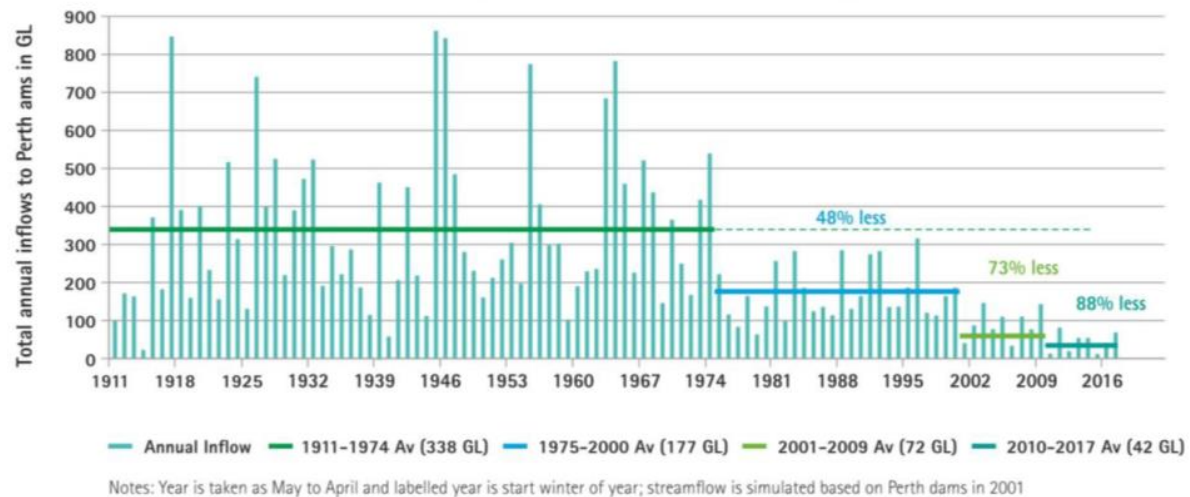

Figure 1 Change in annual rainfall and volume of stream flow into Perth's main dam (Goss, K. personal communication)

This, however, is not the full story. The third lesson revealed by the Perth experience is that if stream flows below a dam need to be maintained, the amount that can be consumed declines by much, much more than the reduction in inflows. As shown in Figure 2, the amount of water needed for base flows, conveyance, and the environment is relatively constant. Although some reductions may be possible, base flow assignments can rarely be reduced proportionally. This means that the impact of a reduction in mean rainfall tends to be greater than most water users appreciate and typically is accompanied by an increase in variability.

When a permanent reduction in supply first occurs, environmental objectives can be compromised but, ultimately, a balance between environmental, social, and economic goals needs to be found. In Perth's case, the long-term response has involved a mixture of notions including the construction of two desalination plants, the re-specification of water entitlement and use regulations, and, most recently, the return of treated sewage to Perth's aquifers. 

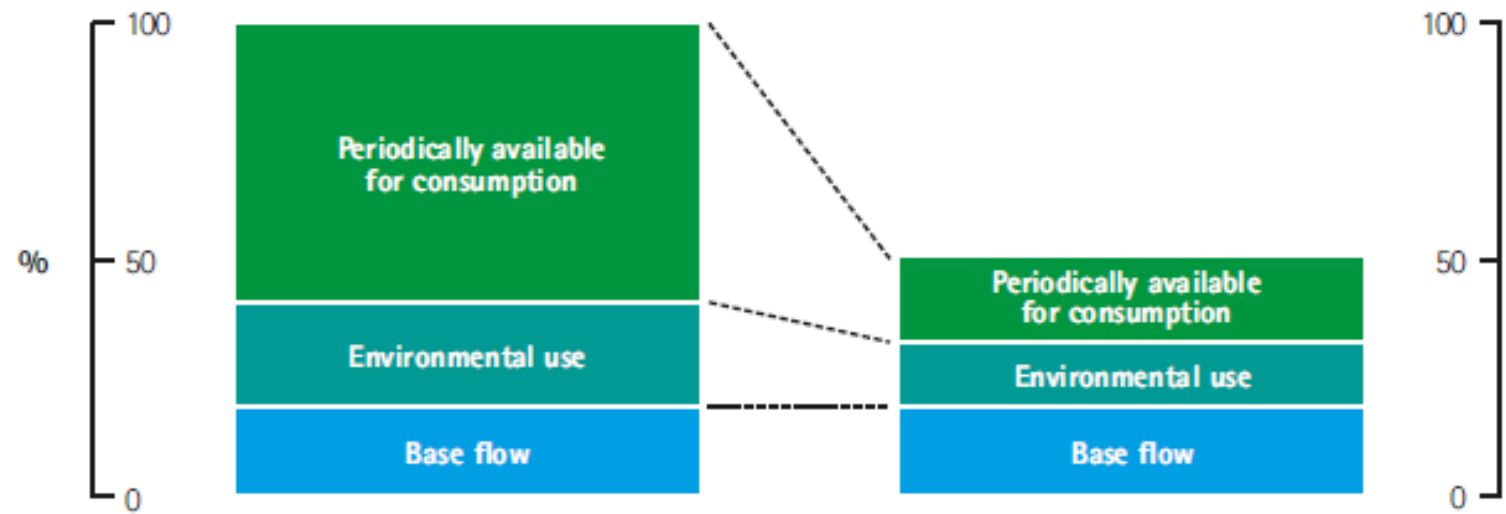

Figure 2 Simple illustration of the effect of a $50 \%$ reduction in run-off on the amount of water available for consumption

Note also that Figure 2 only portrays the 'average' situation. When the impact of increased supply variability or changing demands are added into the range of factors that have to be considered, it becomes clear that the robustness of any water entitlement and allocation system is at least partially a function of its capacity to cope with rapid supply shifts. In such situations, it may be possible temporarily to reduce the volume of water that needs to be set aside for environmental use. However, in many, if not most cases, it is not possible to reduce base flow.

Finally, in passing it needs to be noted that run-off is also a function of land use. Events such as a fire over a large area, construction of contour banks, and conversion of grassland to a timber plantation can all have permanent adverse effects on river flow and aquifer recharge (Young and McColl, 2008).

\section{Return flow reduction and water-use efficiency}

As shown in Figure 3, water use involves the transfer of water to the air via evaporation and transpiration coupled with the return of a significant volume of water to an aquifer, river, or stream. Unfortunately, when pressed to find a quick solution to increasing water scarcity, it is common for community leaders to recommend the adoption of 'more efficient' practices on the assumption that this will 'save' water, even though this has been shown to rarely be the case (Perry and Steduto, 2017). Increases in water-use efficiency are associated typically either with an on-site expansion of the area irrigated with the result that total water use remains the same and/or the transfer of the saved water to another user with the result that no net water-use saving is made (Grafton et al., 2018; Warda and Pulido-Velazquez, 2008). Sometimes referred to as the 'rebound effect' (Berbel et al., 2015), the reason for this is that most water allocation systems authorise the taking of a 'gross' amount of water without considering impacts on the 'net' amount of water used.

When a 'gross' allocation system is used, typically water allocations are specified as an authorisation to a take a volume of water from a water resource and use it, without regard to the amount which returns to a river and/or aquifer. As is done in much of the western United States and in order to protect return flows, one alternative approach is to define each person's entitlement as a 'net' entitlement system and formally account for changes in the amount of water that returns to an aquifer on a user by user basis.

As shown in Figure 3a and b, consumptive water use involves evaporation and transpiration and, in addition to this, changes in return flows need to be managed. That is, unless the gross amount that a person is allowed to take is reduced as water-use efficiency is increased, the net amount of water used must be expected to increase. As shown in Figure 3, an increase in water-use efficiency from $50 \%$ to $90 \%$ results in an increase in water use from 500 to $900 \mathrm{ML}$. That is, the increase in water-use efficiency 
nearly doubles that amount of water that is consumed - unless, of course, the permitted total take is reduced by a compensating amount. ${ }^{7}$

In robust water-sharing systems, the impact of increases in water-use efficiency are managed either by reducing the total amount of water that may be extracted as water-use efficiency increases or by defining rights in net terms.

In the past, because it is very expensive to measure return flows, rules of thumb have been used to convert metered volumes into an estimate of the amount of water that is used and that which returns back to a water resource. ${ }^{8}$ Recent improvements in remote sensing technology, however, mean that it is now possible to reliably estimate consumption at the field level. Typically, this involves the use of software that combines remotely sensed data with land ownership data to estimate evapotranspiration. As field-scale remotely sensed data are now available every few days, a high degree of accuracy can be achieved. Meters, however, are still needed to separate groundwater use from surface water use and track use inside buildings. These new approaches also require continuous access to current land ownership data. When this technology is not available, the previously mentioned practice of reducing allocations per share as the average technical efficiency of water use in a district increases may be more appropriate.

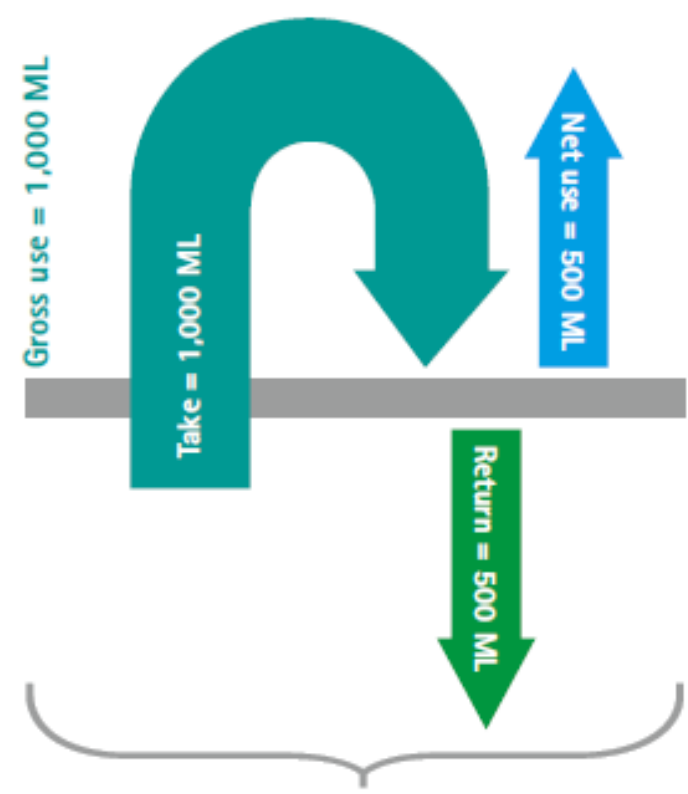

Figure 3a. 'Inefficient' water use

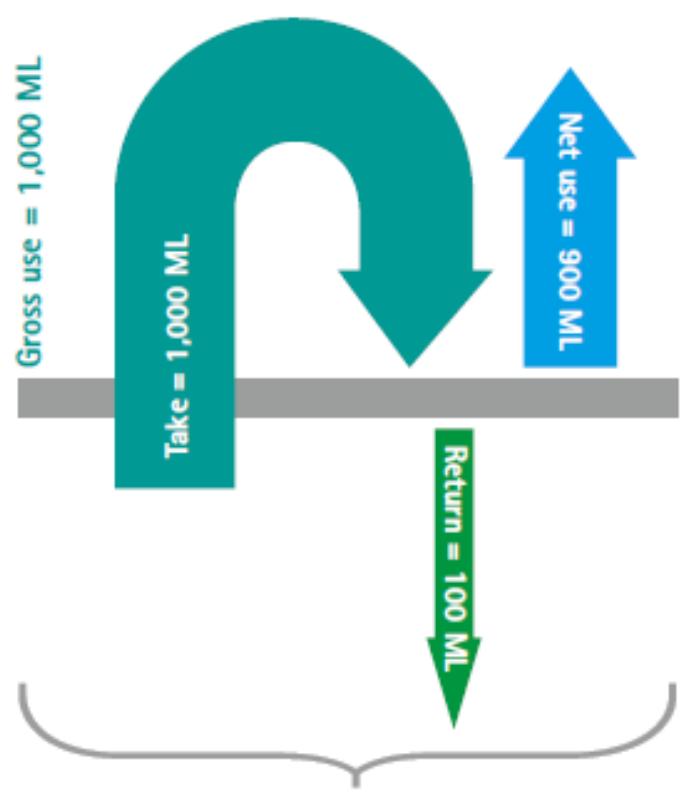

Figure 3b. 'Efficient' water use

Figure 3 Impact of increased water efficiency on the net amount of water used

\section{System design}

A significant proportion of rivers that cross international boundaries do not have a water-sharing agreement in place. ${ }^{9}$ In the Mekong River, for example, no robust sharing system exists. Indeed, two of the six countries that the Mekong River flows through have yet to join the Commission established to

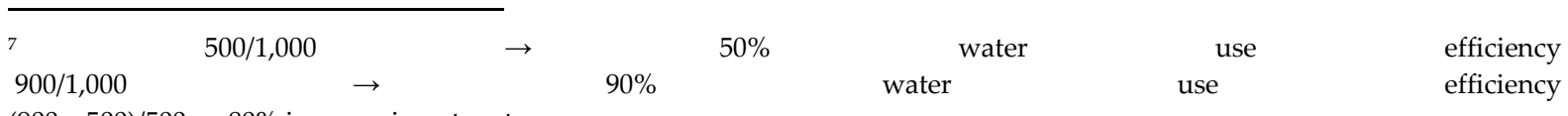

$(900-500) / 500 \rightarrow 80 \%$ increase in net water use

${ }^{8}$ Note that this is not always the same water resource. In such a situation, entitlements to access the source are reduced by the amount taken and then the estimated return flow credit to the receiving water resource.

${ }^{9}$ For more information on transboundary sharing arrangements in Asia, see Moerlins et al. (2008) and Puri (2001). 
facilitate the exchange of information and encourage cooperation. ${ }^{10}$ Similarly, the US State of California has only just started to bring limits on groundwater use into play - even though significant depletion, sea water intrusion, and land subsidence are occurring.

Whatever method is chosen to allocate water to users, usually the first step is to decide which water can be used and which water needs to be left to maintain an adequate flow and to supply essential ecosystem services. This quantity of water is variously known as the 'conveyance' or 'base flow' water needed to maintain a river. In the United Kingdom, this base flow is known as 'hands-off' flow. When the flow rate or, more pragmatically, the water level is less than a pre-specified height, the taking of water from a river or an aquifer is prohibited. ${ }^{11}$

As suggested in Figure 4, the arrangements used to access flood water may be best separated from the arrangements used to manage use during periods when water is scarce. The reason for this is that, in some legal systems, if a person is given a right to take flood water, they may find themselves liable for the damage that 'their' water imposes on others. In these systems, rights to access flood water are typically managed via regulation so that users of this water cannot be held liable for flood damage on the grounds that they would have caused it by failing to take enough water to stop the damage from occurring. In some systems, all flood water is left to the environment. In other systems, capture and storage of flood water is allowed on a 'first come first served' basis.

It is informative to note also that, as more dams (and water retention systems) are built, the proportion of the water that can be managed increases and, hence, the maximum volume of water that can be made available for consumptive use can be increased (see Figure 4).

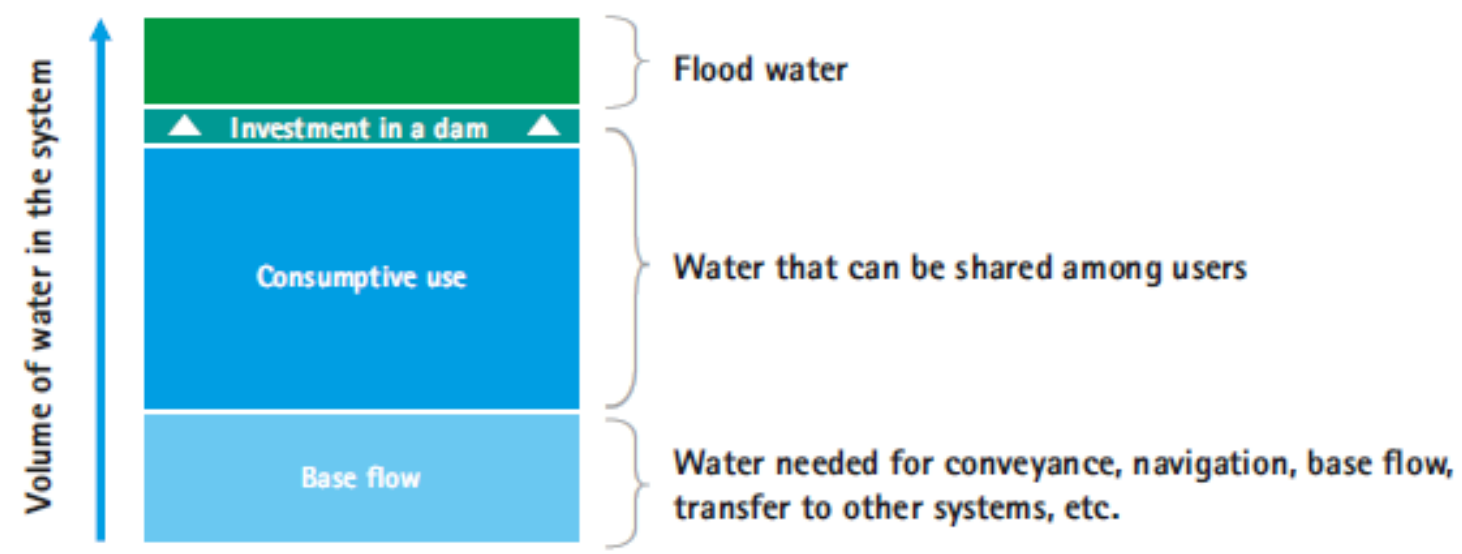

Figure 4 Stylised illustration of a robust water-sharing framework

\section{Basin and aquifer wide versus local sharing systems}

Having identified the boundaries of a system, the next logical step in the development of a robust sharing system is to determine if the entire system can be managed by a single entity or whether a hierarchial structure is needed. Although it may seem easier to begin with a system-wide design, in practice - and as is being done with groundwater in California - there is a strong argument for beginning at the local level and then using a separate process to refine or re-specify system-wide sharing rules. In recognition of the need to bring an end to a significant array of groundwater depletion, land subsidence, and sea water intrusion problems, California enacted legislation in 2014 that would enable local communities to put in place locally controlled groundwater allocation and management systems. Several hundred agencies have now been formed and all these agencies are now in the process of working out how to share access to that part of the state's many groundwater resources under their control. (A parallel process is being used to sort out sub-basin and basin-wide sharing agreements.)

\footnotetext{
${ }^{10}$ The Mekong River passes through China, Burma (Myanmar), Laos, Thailand, Cambodia, and Vietnam. China and Myanmar have yet to join the Mekong River Commission. See http://www.mrcmekong.org/about-mrc/ for more information.

${ }^{11}$ See https://data.gov.uk/dataset/hands-off-flow-surface-water-abstractions
} 


\section{Unbundling}

When setting up a water-sharing system, one of the key questions to be resolved is that of how to define each user's entitlement and whether or not to begin issuing entitlements to take:

- $\quad$ maximum volume; or

- $\quad$ a share of the available resource.

History suggests that, as a general rule, users prefer to be assigned an entitlement to a maximum volume that preserves their options. In practice, however, this often results in over-use and comes at the expense of those who come later. From a community rather than an individual perspective, all will be better off when all users are given an entitlement to a share and volumetric allocations are made periodically in proportion to the number of shares held. This process, sometimes known as an unbundled system, enables rapid low-cost adjustments to be made, makes it possible for new demands to be accommodated, and can be used to encourage investment.

Unbundling, when adopted in its fullest sense, involves the separation of a licence into its core components and the efficient management of each component.

An unbundled water-sharing system consists of the following:

1. Statutory plans are used to define the boundaries of each of the water resource to be shared, the ways that water is to be distributed between each connected water resource, determine the maximum number of shares that may be issued, and define how allocations are to be made as supplies change.

2. Shares are issued to users or, when this is not possible, to the water utility responsible for maintaining the infrastructure used to supply water to users.

3. Share ownership is determined by recording names in a share register that is similar in form to the share registers used to determine who owns what proportion of a company.

4. Water accounts are established and used to record how much water has been allocated to any water user, how much has been used, and how much more may be taken.

5. Allocations are made to water accounts in proportion only to the number of shares held by an account holder. Water is credited to the account as it becomes available and debited either as it is used or when transferred, at an appropriate exchange rate, from one account to another.

6. Use approvals/permits are used to authorise the taking and use of water at a specific location on the condition that the quantity taken can be debited from a nominated water account and that all site-specific and system-wide use conditions are complied with.

7. Adjustment is facilitated (a) within a defined water resource by allowing the transfer of shares and allocations from one user to another and (b) between connected resources by allowing the transfer of allocations at an appropriate exchange rate and time delay to allow withdrawal from the other resource without adverse impact on other users.

In an unbundled system, great care is taken to fully specify each of the above components so that they can be managed by different entities and at different scales. No attempt is made to record every change on a single licence or in a single file. Instead:

- a share register is used to determine who owns what and how to distribute allocations among shareholders

- $\quad$ water accounts are used to determine how many allocations a user still has access to

- $\quad$ permits are used to control how and where water is used.

Typically, shares are issued as an ongoing or perpetual entitlement; allocations made on a daily, weekly, or annual basis; and use approvals used to define where and how water may be taken and used. As systems are developed, often the first step is to assign shares to regions and/or communities and then to individuals. It is possible, however, to start at the individual level and aggregate back upwards. 
At the individual level, and in fully developed systems, entry into the water management system and the expansion of water use are facilitated by allowing the trading and/or re-allocation of shares. Efficient day to day management of water use is facilitated by making allocations and allowing the transfer of these allocations from one user to another. In state-of-the-art systems, investment and innovation are encouraged by allowing the low-cost registration and guaranteed protection of a financial interest in the shared register.

\section{Share transfers and re-allocation}

In an unbundled water-sharing system, shares enable shareholders to protect their long-term interest in a resource such as an orange grove, a rice paddy, or the supply of water to a city.

Once shares have been allocated and issued to users and/or user groups, adjustment is possible only through re-allocation of shares. In basins and aquifers where this approach has been taken, administrators interested in facilitating structural adjustments have a number of options available to them. In practice, they can:

- allow the voluntary transfer of shares from one party to another

- $\quad$ periodically take back a percentage of each shareholding

- claw back a proportion of shares whenever a holding is transferred from one party to

another

undermine the security of the existing sharing and simply decide to issue more shares without increasing supply capacity.

When considering each of these options, options one and two - voluntary transfers and percentage reductions - have the advantage that they are economically efficient and encourage efficient investment. The third - effectively a 'tax on transfers' - is economically inefficient as it taxes and, hence, discourages adjustment. Although the fourth option is common in many countries, it tends to result eventually in over-use with adverse effects on other users and/or the environment. This approach is not recommended.

Note that when the transfer of water from one person to another is opposed for social reasons, the second option - a regular across the board reduction of the number of shares held by all users - enables the re-allocation of water shares without compromising related sustainability and efficiency objectives.

\section{Supply risk management}

In areas where the quantity of water that can be made available for use varies considerably, robust sharing systems include a suite of arrangements designed to encourage all users to plan for droughts and other forms of supply risk. The inclusion of an opportunity to transfer allocations from one user to another is one such arrangement but often users prefer a built-in priority system so that long- and shortterm supply risks can be managed separately. In theory, this can be achieved by establishing at least two classes of shares: a high-priority class and a second lower-priority class. A nominated volume of allocations is then allocated to these shares before any water is allocated to the lower-priority class.

In practice and provided allocation transfer costs can be kept low, there appears to be a strong economic case for at least three priority pools and for setting a limit on the maximum volume of water that may be allocated to all but the lowest priority pool (see Figure 5). Under such a pooling arrangement, supply risk can be managed efficiently by enabling each water user to determine how many they should hold of:

$$
\begin{array}{ll}
\text { - } & \text { high-priority shares } \\
\text { - } \quad \text { medium-priority shares } \\
\text { - } \quad \text { low-priority shares. }
\end{array}
$$

Under such an arrangement, high-priority shareholders would expect to receive the maximum allocation per share in almost every year, and medium-priority shareholders would receive the full 
allocation in, say, 8 out of 10 years. Low-priority shareholders would, however, only expect to receive their full allocation in, say, 5 out of 10 years.

In some parts of the world, access to 'high-priority' water is reserved for urban and industrial purposes. While admirable in intent, because it appears to give preference above all else to the provision of access to drinking water, this approach is less robust than one that places an absolute limit on the volume of water that may be allocated to each security pool, making an initial allocation and then allowing this distribution to be adjusted over time. When this approach is taken, city planners, for example, are required to proactively manage long-term supply risks and not assume that they may force the transfer of water to them whenever the next drought comes along.

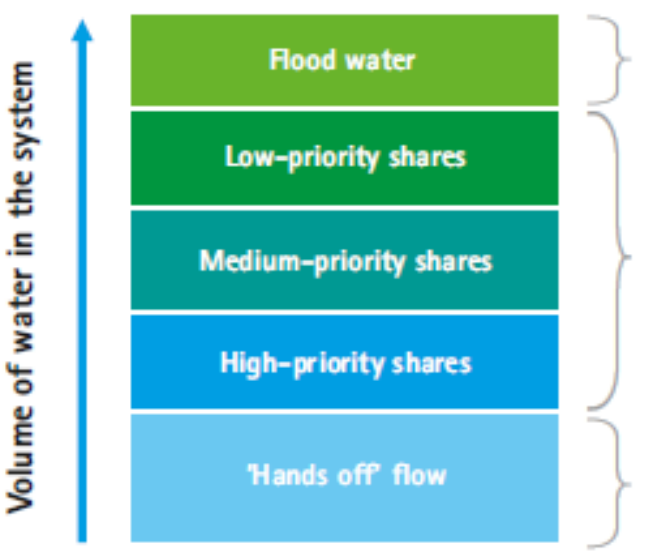

Flood water

Water available for consumptive use can be split into three or more priority sharing pools

Water needed for conveyance, navigation, base flow, transfer to other systems, etc.

\section{Figure 5 Modification of a sharing system to enable more efficient management of supply risk by defining priorities}

System-wide sharing agreements, as noted earlier, also play a unique role in ensuring that enough water is put aside to maintain essential ecological functions and that the needs of non-consumptive uses, such as shipping, recreational boating, and traditional fishing are met.

\section{Traditional and 'de minimis' uses}

So far, the arrangements set out in this paper have focused on formal water sharing arrangements. In most systems, however, there is a significant number of uses that are either too expensive to manage or have been defined by law as a prior right in the sense that those responsible for these forms of use are entitled by law to take water. Usually, a suite of regulations are used to keep the impact of such uses on others under control. Examples of such uses, include the taking of water for domestic, livestock, and other traditional purposes.

Known in some parts of the United States as 'de minimis' uses, the volume of water consumed by these uses can be included in the sharing system by requiring a legal entity, such as a local city council, to hold sufficient shares to offset the impacts of these uses on the size of the consumptive pool (Young and McAteer, 2017). As suggested by Schriener and van Koppen (2018), this same arrangement can also be used to recognize and include and account for customary rights in a robust water sharing system. One of the simplest ways of including and accounting for such uses, is to assign the highest priority to these systems and regulate their use (Figure 6). Where use is expected or might increase through time, however, robustness requires such uses to be managed and if it increases, to find a way to reduce other uses. One of the simplest ways to do this, is to require a local government or other similar authority to hold shares on behalf of these users and ensure that enough shares and allocations are held to ensure that this form of use is fully accounted for.

When a local council or its equivalent is required to hold sufficient shares to allow management of traditional and de minimis uses, they have an incentive to manage these impacts. Where appropriate and with the support of local users, for example, this arrangement can be used to generate interest in ensuring that all users have access to a potable mains water supply. 


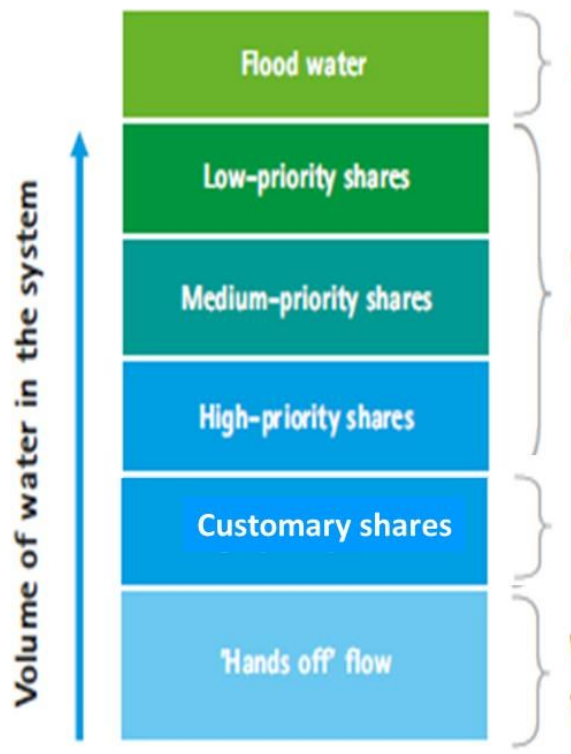

Flood water

Water available for consumptive use can be split into

three or more priority sharing pools

Water held by a council or other equivalent body on behalf of users who have a customary right to access and use water.

Water needed for conveyance, navigation, base flow, transfer to other systems, etc.

Figure 6 A sharing system that requires a local council to hold shares on behalf of customary water users

The arrangement set out in Figure 6 gives legal recognition to customary rights, gives these users a prior or preferential access right in a manner that forces all others involved in the system to recognise and fully account for the impact of these customary uses on the extent of opportunities available to other shareholders.

\section{Managing variability}

Earlier in this paper, it was recognised that when water first becomes scarce, often the first response is to build one or more dams in an attempt to reduce supply variability. Dams allow flows and, hence, allocations to be made when water otherwise would be scarce. When one or more dams are built, it is important to decide when and how this water is be allocated to shareholders. In robust water sharing systems the rules used to guide the release of water from a dam are set out in a statutory plan. When this is done, however, and the trading of water allocations is allowed, care needs to be taken to decide whether or not to allow unused allocations to be carried forward from one allocation season to the next. If the carry-forward of unused water allocations is not allowed then each user has an incentive to either use or transfer the allocation to some-one else. While this may seem rational, water release rules need to take full account for such an arrangement. The alternative approach is to combine a statutory set of dam water release rules with a mechanism enabling the carry-forward of water from one allocation period to the next when this unused water can be left in dam for use in a sub-sequent period with adjustment of evaporation, dam spills and any other losses that might occur.

\section{Administrative arrangements}

When discussing the most appropriate administrative arrangements to put in place, great care is necessary as each arrangement depends upon the nature of national, regional, and local legal arrangements and customs, and these tend to vary from one country to another. Care also needs to be taken to avoid confusion as to whether or not the word 'governance' refers to the entire management system or simply the administrative structures used to manage water use. In this paper, the term governance refers to administrative arrangements. When this approach is taken, it is possible to begin developing checklists and searching for gaps in existing administrative arrangements (GWP, 2003, 2008; OECD, 2015a, 2015b). 
Although much of the detail is too complex for consideration in this paper, guidelines such as those produced by the OECD (Appendices One and Two) tend to emphasise:

- $\quad$ importance of building and retaining trust - reputations that have taken years to develop can be lost in seconds

- $\quad$ subsidiarity - the idea that the role of a system-wide decision-making entity should be limited to those considerations that cannot be taken locally and that all other considerations should be left to local decision makers

- increasing adaptive capacity by establishing administrative and consultative mechanisms that enable decisions to be taken as quickly as supply and demand conditions change

- $\quad$ structures that minimise opportunities for insider trading and manipulation by powerful interests.

When it comes to the importance of maintaining trust, Ostrom's principles (Box 1) suggest the need for the use of graduated sanctions and, when considered carefully, suggest the need to allow those responsible for accidental over-use, for example, to be able to make good and, also, for initial reliance on civil rather than criminal penalty processes when rules are violated.

\section{Charging for service provision}

As revealed by Ostrom's many case studies of experiences in the management of common property resources (see Box 1), robustness can be increased by ensuring a close alignment between benefits received and the costs of holding a water entitlement and using resultant allocations. Challenging common practice, Ostrom's work also suggests that a water-sharing system will be more robust if the system is self-funding. That is, the people involved in managing the system are not dependent upon funding from a central government or donor. To this end, economists often recommend that the cost of maintaining any system be partitioned into fixed and variable costs and that:

- $\quad$ fixed costs are recovered in proportion to the number of shares held

- variable costs are recovered in proportion to the volume of water taken

- $\quad$ the average cost of processing share transfers, transferring allocations from one water account to another, etc. be recovered from the people involved in each transaction.

Ostrom's work also suggests that robustness can be increased in some systems by requiring all users to contribute labour - as is done in the Subak systems found in Indonesia (Roth 2011).

\section{Adding value, revealing value, and increasing opportunity}

As mentioned before, the need to value water in decision making has been underlined by several observers and practitioners, most notably by the High-Level Panel on Water (2018). As reasoned by the Panel, the more valuable something is the more it is likely to be cared for and used with care. Watersharing options that increase recognition of the value of water by individual users may include the creation of a share register of guaranteed integrity and the issuing of shares to the environment.

\section{A single share register}

Once a formal sharing system has been put in place, value can be increased by ensuring the integrity of share registers and allowing these shares to be mortgaged in the same way that it is possible to mortgage land (Young and McColl, 2005).

Consistent with the concepts found in many qanat systems, one of the simplest reforms that can be introduced in any region is to run a process that converts all paper-based water licences into a centralised electronic register of guaranteed integrity. Once this has been done, there is no need for any arguments and, at the same time, separating any use approval embedded in the licence from the 
mechanisms used to define each licence holder's share. Thus, the value of each share can be expected to rise and it might be used to finance investment (Young and McAteer, 2017).

\section{Environmental shares}

It is possible to build systems that recognise the right of a river system or an aquifer to defend itself, as has recently been successfully argued in the case of the Whanganui River in New Zealand.

One approach for countries to administratively implement this is to allocate or transfer shares to an environmental trust. When this is done, whenever water is allocated to a conventional water user, some water must be allocated to the environment and formal environmental water accounts must be established. Although still new in their development, once this is done, environmental managers arguably have an incentive to improve the effectiveness of environmental water use and take an active role in deciding when and how this water is used. ${ }^{12}$ Figure 7 sets out a general framework for the inclusion of the environment as a shareholder. The approach is consistent with an emerging interest in giving rights to a river or an aquifer rather than to the public as a whole. This approach is similar to that recommended earlier for the management of traditional and de minimis uses.

I
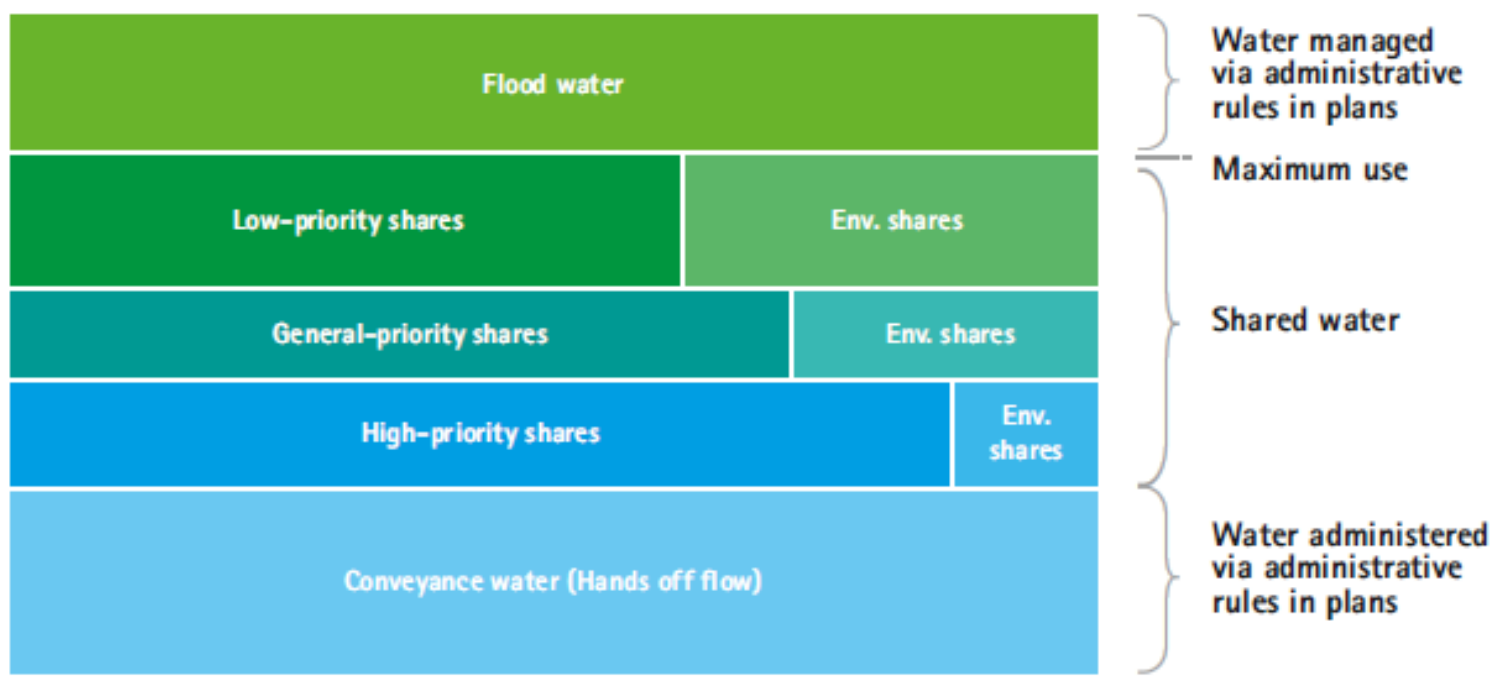

Figure 7 Framework for the allocation of shares to the environment

\section{Bank-like allocation trading}

The last issue to raise is the question of how to best allow the trading of water allocations from one person to another. A vast amount of literature has been written on this topic. When examined carefully, however, it becomes clear that trading becomes the norm in robust water sharing systems and tend to emerge as they have in the Qanat systems found in the Middle East and in systems in Australia and some parts of the United States of America.

In robust water sharing systems all water use is monitored and each user is given a water account that looks like and resembles a bank account. Water as soon as it is allocated to a shareholder is credited to that shareholder's water account and, as soon as it occurs, the amount taken is debited from this account. When such a system is in place, the transfer of water from one account to the next can achieved simply by logging into a water account and requesting that some or all of the water allocations in that

\footnotetext{
${ }^{12}$ When considering this opportunity, care needs to be taken to differentiate between the consumptive use of water for environmental purposes and benefits that flow from the presence of water. Flow benefits can be achieved efficiently via rules that require sufficient water to ensure adequate water for conveyance etc. To supply the evaporation and transpiration of water for environmental purposes, in some parts of Australia and the United States, governments and non-government organisations are now experimenting with the formal allocation of shares to the environment.
} 
account be transferred to another account at an exchange rate that takes full account of any losses associated with the transfer of water from one account to another.

\section{Concluding comments}

The purpose of this paper is to encourage water managers and users to consider the case for increasing the robustness of their water-sharing arrangements within the context of valuing water principles. The paper recognises that discussions about water-sharing arrangements tend to be personal and often politically sensitive. Issues of fairness and views about the most appropriate way to allocate opportunities to access water quickly come to the forefront. Failure to find a way forward, however, is one of the prime causes of water crises potentially resulting in a vicious cycle of conflict and deteriorated water and environmental ecosystems around the world.

As a way forward, it is suggested that readers of this paper begin by asking whether or not there is a case for transitioning to a new system and/or modifying the existing system in their own context. If the answer is yes, then the next step is to commence a formal review process. Formal reviews take time; however, it needs to be appreciated that the costs of procrastination can be high.

Finally, attention is drawn to the fact that one of the merits of a formal sharing system is that it is always possible to start locally and - once the merits of progress have been demonstrated - this can become the basis for considering the case for wider reform across multiple river basins, states, nations, and beyond.

\section{References}

Anonymous (2014) Dictionary of Jargon. Routledge Revivals.

Anonymous (2018) Brasilia Declaration of Judges on Water Justice. The 8th World Water Forum, Brazil.

Barghouti, S. (2006). Case Study of the Aral Sea Water and Environmental Management Project: An Independent Evaluation of the World Bank's Support of Regional Programs. The World Bank, Washington DC.

Berbel, J., Gutiérrez-Martín, C., Rodríguez-Díaz, J.A., Camacho, E. and Montesinos, P. (2015) Literature review on rebound effect of water saving measures and analysis of a Spanish case study. Water Resources Management, 29(3): 663-678.

Bruns, B.R., Ringler, C. and Meinzen-Dick, R. (2005) Water Rights Reform: Lessons for Institutional Design. International Food Policy Institute, Washington DC.

Grafton, R.Q., Williams, J., Perry, C.J., Molle, F., RIngler, C., Steduto, B., Udall, B., Wheeler, S.A., Wang, Y., Garrick, D. and Allen, R.G. (2018) The paradox of irrigation efficiency: Higher efficiency rarely reduces water consumption. Science 361:748750.

GWP (2003) Effective Water Governance, Background Paper No. 7. Global Water Partnership (GWP), Stockholm.

GWP (2008) Water Finance and Governance, Background Paper No. 12. Global Water Partnership (GWP), Stockholm.

GWP (2016) Increasing Water Security: the Key to Implementing the Sustainable Development Goals, Background Paper No. 22. Global Water Partnership (GWP), Stockholm.

High Level Panel on Water (2018) Making every drop count: outcome document. aquaforall.org/makingevery-drop-count/

Moerlins, J.E., Khankhasayev, M.K., Leitman, S.F. and Makhmudov, E.J. (eds.) (2008) Transboundary Water Resources: A Foundation for Regional Stability in Central Asia. Springer, New York and London.

Molden, D. (ed) (2007) Water for Food, Water for Life: A Comprehensive Assessment of Water Management in Agriculture. Earthscan, London and International Water Management Institute, Colombo. 
Moore, S.M. (2018) Subnational Hydropolitics: Conflict, Cooperation, and Institution-Building in Shared River Basins. Oxford University Press, Oxford.

OECD (2015a) OECD Principles on Water Governance. OECD, Paris. www.oecd.org/water

OECD (2015b) Water Resources Allocation: Sharing Risks and Opportunities, OECD Studies on Water,

OECD, Paris. www.oecd.org/water

Ostrom, E. (2010) Beyond markets and states: polycentric governance of complex systems. The American Economic Review, 100: 1-33.

Oxford Advanced Learners Dictionary

https://www.oxfordlearnersdictionaries.com/definition/english/robustness

Oxford Living Dictionaries (2018) https://en.oxforddictionaries.com/definition/robustness

Perry, C.J. and Steduto, P. (2017) Does Improved Irrigation Technology Save Water? A Review of the Evidence. FAO, Cairo.

Puri, S. (ed.) (2001) Internationally Shared (Transboundary) Aquifer Resources Management, Their Significance and Sustainable Management. UNESCO, Paris.

Roth, D. (2011) The Subak in diaspora: Balinese farmers and the Subak in South Sulawesi. Human Ecology, 39(1): 55-68.

Schreiner, B. and van Koppen, B. (2018) Establishing hybrid water use rights systems in Sub-Saharan Africa. Pegasys Institute and International Water Management Institute.

Tang, S.Y. (1992) Institutions and Collective Action. Center for Self-Governance, San Francisco.

Turton, A.R. (1999) Water Scarcity and Social Adaptive Capacity: Towards an Understanding of the Social Dynamics of Water Demand Management in Developing Countries. MEWREW Occasional Paper No. 9. Water Issues Study Group, School of Oriental and African Studies, London.

UN (2018) Sustainable Development Goal 6 Synthesis Report 2018 on Water and Sanitation. United Nations (UN), New York.

Ward, P. (1968) The origin and spread of qanats in the old world. Proceedings of the American Philosophical Society, 112(3): 170-181.

Warda, F.A. and Pulido-Velazquez, M. (2008) Water conservation in irrigation can increase water use. Proceedings of the National Academy of Science, 105(47): 18215-18220.

Wheeler, S., Loch, A., Crase, L., Young, M. and Grafton, R. (2017) Developing a water market readiness assessment framework. Journal of Hydrology, 552: 807-820.

Young, M. and McAteer, B. (2017) Sharing Groundwater: A Robust Framework and Implementation Roadmap for Sustainable Groundwater Management in California. NI WP 17-02. Duke University, Durham, NC. http://nicholasinstitute.duke.edu/http://nicholasinstitute.duke.edu/publications

Young, M.D. (2010) Environmental effectiveness and economic efficiency of water use in agriculture, the experience of and lessons from the Australian Water Reform Programme. Background report prepared for OECD (2010) Sustainable management of water resources in agriculture. OECD, Paris. www.oecd.org/water

Young, M.D. (2012) A Framework for the Allocation and Management of Water in England and Wales. University College London Environment Institute, London and The University of Adelaide, Adelaide.

Young, M.D. and McColl, J.C. (2005) Defining tradable water entitlements and allocations: a robust system. Canadian Water Resources Journal, 30(1): 65-72. 
Young, M.D. and McColl, J.C (2008) Double trouble: the importance of accounting for and defining water entitlements consistent with hydrological realities. The Australian Journal of Agricultural and Resource Economics, 53: 19-35. 


\section{Appendix One}

\section{OECD water governance principles}

\section{Enhancing the effectiveness of water governance}

1. Clearly allocate and distinguish roles and responsibilities for water policy-making, policy implementation, operational management, and regulation, and foster co-ordination across these responsible authorities.

2. Manage water at the appropriate scale(s) within integrated basin governance systems to reflect local conditions and foster co-ordination between the different scales.

3. Encourage policy coherence through effective cross-sectoral co-ordination, especially between policies for water and the environment, health, energy, agriculture, industry, spatial planning, and land use.

4. Adapt the level of capacity of responsible authorities to the complexity of water challenges to be met, and to the set of competencies required to carry out their duties.

\section{Enhancing the efficiency of water governance}

5. Produce, update, and share timely, consistent, comparable, and policy-relevant water and water-related data and information, and use it to guide, assess, and improve water policy.

6. Ensure that governance arrangements help mobilise water finance and allocate financial resources in an efficient, transparent, and timely manner.

7. Ensure that sound water management regulatory frameworks are effectively implemented and enforced in pursuit of the public interest.

8. Promote the adoption and implementation of innovative water governance practices across responsible authorities, levels of government, and relevant stakeholders.

\section{Enhancing trust and engagement in water governance}

9. Mainstream integrity and transparency practices across water policies, water institutions, and water governance frameworks for greater accountability and trust in decision making.

10. Promote stakeholder engagement for informed and outcome-oriented contributions to water policy design and implementation.

11. Encourage water governance frameworks that help manage trade-offs across water users, rural and urban areas, and generations.

12. Promote regular monitoring and evaluation of water policy and governance where appropriate, share the results with the public, and make adjustments when needed.

Source: OECD (2015a) 


\section{Appendix Two}

\section{OECD ‘Health check' for water resources allocation}

1. Are there accountability mechanisms in place for the management of water allocation that are effective at a catchment or basin scale?

2. Is there a clear legal status for all water resources (surface, groundwater, and alternative sources of supply)?

3. Is the availability of water resources (surface, groundwater, and alternative sources of supply) and possible scarcity well understood?

4. Is there an abstraction limit ('cap') that reflects in-situ requirements and sustainable use?

5. Is there an effective approach to enable efficient and fair management of the risk of shortage that ensures water for essential uses?

6. Are adequate arrangements in place for dealing with exceptional circumstances (such as drought or severe pollution events)?

7. Is there a process for dealing with new entrants and for increasing or varying existing entitlements?

8. Are there effective mechanisms for monitoring and enforcement, with clear and legally robust sanctions?

9. Are water infrastructures in place to store, treat, and deliver water in order for the allocation regime to function effectively?

10. Is there policy coherence across sectors that affect water resources allocation?

11. Is there a clear legal definition of water entitlements?

12. Are appropriate abstraction charges in place for all users that reflect the impact of the abstraction on resource availability for other users and the environment?

13. Are obligations related to return flows and discharges properly specified and enforced?

14. Does the system allow water users to reallocate water among themselves to improve the allocative efficiency of the regime?

Source: OECD (2015b) 


\section{Appendix Three}

The concepts of valuing water are embedded and integral to developing robust water-sharing systems. Valuing water means recognising and considering all the benefits provided by water that encompass economic, social, and ecological dimensions. It takes many forms appropriate to local circumstances and cultures. Safeguarding the poor, the vulnerable, and the environment is required in all instances. Valuing water can help balance the multiple uses and services provided by water and inform decisions about allocating water across uses and services to maximise well-being. Allocation can take different forms, such as regulation and economic instruments that signal scarcity, avoid waste, and promote conservation. Valuing water can make the cost of pollution and waste apparent and promote greater efficiency and better practices as water managers begin to implement water-sharing mechanisms. Any use of water relies on infrastructure, green or grey. Pricing is not synonymous with value but is one way of covering costs, reflecting part of the value of these uses, and ensuring adequate resources and finance for related infrastructure services.

\section{Principles for valuing water developed by the High-Level Panel on Water}

1. Recognise and embrace water's multiple values

Identify and take into account the multiple and diverse values of water to different groups and interests in all decisions affecting water.

There are deep interconnections between human needs, social and economic well-being, spiritual beliefs, and the viability of ecosystems that need to be considered.

\section{Reconcile values and build trust}

Conduct all processes to reconcile values in ways that are equitable, transparent, and inclusive. Trade-offs will be inevitable, especially when water is scarce, and these call for sharing benefits among all those affected. Inaction may also have costs that involve steeper trade-offs. These processes need to be adaptive in the face of local and global changes.

\section{3. $\quad$ Protect the sources}

Value, manage, and protect all sources of water, including watersheds, rivers, aquifers, and associated ecosystems, and use water flows for current and future generations. There is growing urgency to protect sources, control and prevent pollution, and address other pressures across multiple scales.

\section{Educate to empower}

Promote education and public awareness about the intrinsic value of water and its essential role in all aspects of life.

This will enable broader participation, water-wise decisions, and sustainable practices in areas such as spatial planning, development of infrastructure, city management, industrial development, farming, protection of ecosystems, and domestic use.

\section{Invest and innovate}

Ensure adequate investment in institutions, infrastructure, information, and innovation to realise the many different benefits derived from water and reduce risks.

This requires concerted action and institutional coherence. It should harness new ideas, tools, and solutions while drawing on existing and indigenous knowledge and practices in ways that nurture the innovative leaders of tomorrow.

Source: High-Level Panel on Water (2018)

Water is more than a substance - it carries multiple values and meanings. These are expressed in spiritual, cultural, and emotional terms and found in the heritage of water language, norms, and artefacts. These reflect the deep perceptions, need for connections and participation of all members of society. Therefore, water-sharing arrangements that strive to make water available for its many uses and users requires tools and institutions to transform it from a natural resource to one providing 
services and then to recover and return it safely back to nature; embedding valuing water principles into the steps needed for comprehensive water-sharing. 
Global Water Partnership (GWP) Secretariat

PO Box 24177

10451 Stockholm, SWEDEN

Visitor's address: Linnégatan 87D

Phone: +46812138600

Email: gwp@gwp.org

Websites: www.gwp.org, www.gwptoolbox.org 